\title{
Thermal Properties of Multilayer Nanocomposites Based on Halloysite Nanotubes and Biopolymers
}

\author{
Vanessa Bertolino, Giuseppe Cavallaro* *(i), Stefana Milioto, Filippo Parisi ${ }^{(1)}$ and \\ Giuseppe Lazzara ${ }^{(D)}$ \\ Dipartimento di Fisica e Chimica, Università degli Studi di Palermo, Viale delle Scienze, pad. 17, 90128 Palermo, \\ Italy; vanessarita.bertolino@unipa.it (V.B.); stefana.milioto@unipa.it (S.M.); filippo.parisi@unipa.it (F.P.); \\ giuseppe.lazzara@unipa.it (G.L.) \\ * Correspondence: giuseppe.cavallaro@unipa.it; Tel.: +39-091-23897962
}

Received: 22 June 2018; Accepted: 9 July 2018; Published: 12 July 2018

\begin{abstract}
This paper reports a novel procedure to fabricate multilayer composite biofilms based on halloysite nanotubes (HNTs) and sustainable polymers. Among the biopolymers, the non-ionic (hydroxypropyl cellulose) and cationic (chitosan) molecules were selected. The nanocomposites were prepared by the sequential casting of ethanol solutions of hydroxypropyl cellulose and aqueous dispersions of chitosan/HNTs. The composition of the bio-nanocomposites was systematically changed in order to investigate the effect of the hydroxypropyl cellulose/HNTs ratio on the thermal properties of the films, which were investigated by differential scanning calorimetry (DSC) and thermogravimetry (TG). DSC studies were conducted in the static air (oxidative atmosphere), while TG measurements were carried out under nitrogen flow (inert atmosphere). The analysis of DSC data provided the enthalpy and the temperature for the oxidative degradation of the bio-nanocomposites. These results were helpful to estimate the efficacy of the well-compacted middle layer of HNTs as a flame retardant. TG experiments were performed at a variable heating rate and the collected data were analyzed by the Friedman's method (non-isothermal thermogravimetric approach) with the aim of studying the kinetics of the hydroxypropyl cellulose degradation in the multilayer nanocomposites. This work represents an advanced contribution for designing novel sustainable nanocomposites with excellent thermal behavior as a consequence of their peculiar multilayer structure.
\end{abstract}

Keywords: halloysite nanotubes; multilayer nanocomposites; biopolymers; hydroxypropyl cellulose; thermogravimetry; differential scanning calorimetry

\section{Introduction}

Halloysite is an emerging nanofiller for the fabrication of smart nanocomposites with specific functionalities useful for several technological purposes, such as anti-corrosion coatings [1-3], food packaging [4-6], remediation [7-11], catalysis [12-15], tissue engineering [16-18], preservation of art-works [19-21], and antimicrobial protection [22,23]. Recent biological studies (by means of both in vivo and vitro tests) proved that halloysite exhibits a low toxicity [24-26]. The chemical formula of halloysite is $\mathrm{Al}_{2} \mathrm{Si}_{2} \mathrm{O}_{5}(\mathrm{OH})_{4} \cdot 2 \mathrm{H}_{2} \mathrm{O}$. From the mineralogical viewpoint, halloysite is a phyllosilicate 1:1, which means that each composed layer is formed of one octahedral sheet of alumina and one tetrahedral sheet of silica [27]. This mineral possesses a hollow tubular shape with a large polydispersity in sizes on the dependence of the geological setting [28]. The length interval is between 50 and $1500 \mathrm{~nm}$, while the external and internal diameters range between 20-150 and 10-15 nm [28]. The chemical composition of the halloysite surfaces is different, being that the inner one is composed of $\mathrm{SiO}_{2}$ groups while the external shell is formed by $\mathrm{Al}_{2} \mathrm{O}_{3}$ groups. Consequently, in the $\mathrm{pH} 2-8$, the cavity possesses a positive net charge, whereas the shell is negatively charged [29]. This peculiarity allows for a 
selective modification of the halloysite surfaces by means of ionic molecules that can be exploited to control its colloidal stability and rheological properties as requested for the numerous applications on tubular nanoparticles [30-33]. Within this, the specific electrostatic interactions between ionic polymers and halloysite affect the thermal and mechanical behaviors of the corresponding nanocomposites prepared by the aqueous casting method [34]. The addition of halloysite nanotubes (HNTs) within anionic polymers represents an efficient strategy to enhance the thermal stability of the biomaterials because the polymeric chains are entrapped within the HNTs lumen [4,34]. This effect was detected for pectin/HNTs [4,35] and alginate/HNTs nanocomposites [34]. Biocomposites based on cationic chitosan and halloysite evidenced suitable performances as scaffolds for tissue engineering $[18,23,36]$ and hydrogel for medical purposes [37]. The literature reports that HNTs are efficient reinforcing fillers for chitosan matrix $[38,39]$. The high dispersibility of halloysite into hydrophilic polymers generated nanocomposite materials with a large wettability and excellent tensile performances in terms of stress at breaking point and elasticity [34]. Nanocomposites based on halloysite and polylactic acid (PLA) showed enhanced barrier properties with respect to the pure biopolymer [40]. Our recent work evidenced that the confinement of HNTs between chitosan layers generated composite biofilms with a relevant flame resistance [41]. It should be noted that the specific functionalities and the physicochemical characteristics of polymer/HNTs nanocomposites are strongly influenced by their mesoscopic structure [42]. Here, we prepared multilayer nanocomposite films formed by three components: two biopolymers (hydroxypropyl cellulose and chitosan) and halloysite (inorganic filler). An intermediate layer of chitosan/HNT was confined between hydroxypropyl cellulose by using a sequential casting procedure performed in different solvents (water and ethanol). The thermal properties of the nanocomposites were investigated by two techniques: thermogravimetry (TG) and differential scanning calorimetry (DSC). The combination of TG and DSC can provide an exhaustive description of the thermal behavior of hybrid systems, including supramolecular complexes [43-45] and polymer/nanofiller composite materials [41,46,47]. Moreover, the mentioned thermal methods are useful within a cultural heritage for the diagnostics [48] and the treatment [20] of artworks. As reported in this paper, TG experiments performed at variable heating rates allow for the determination of the activation energy of the polymer degradation in composite systems $[5,49,50]$. On the other hand, DSC measurements are helpful to investigate the flame retardant action of nanofillers dispersed in a polymeric matrix [41,51].

This paper reports a novel protocol to generate biopolymers/halloysite nanocomposites with a peculiar sandwich-like shape. The promising thermal properties in the inert atmosphere were investigated by thermogravimetric experiments using a non-isothermal approach, while differential scanning calorimetry measurements in static air revealed that the multilayer morphology confers a fire resistance to the nanocomposites. This study provides a contribution to the fabrication of bio-nanocomposites with a controlled structure that can be exploited for engineering and biological applications.

\section{Materials and Methods}

\subsection{Materials}

Chitosan (75-85\% deacetylated, $\mathrm{M}_{\mathrm{w}}=50-190 \mathrm{~kg} \cdot \mathrm{mol}^{-1}$ ), hydroxypropyl cellulose (HPC, $\mathrm{M}_{\mathrm{W}}=80 \mathrm{~kg} \cdot \mathrm{mol}^{-1}$ ), ethanol, and glacial acetic acid are Aldrich products (Sigma-Aldrich, St. Louis, MO, USA). Halloysite nanotubes (HNTs; $\mathrm{M}_{\mathrm{w}}=294.19 \mathrm{~g} \cdot \mathrm{mol}^{-1}$ ) are from Imerys Ceramics New Zeeland Limited (Kerikeri, New Zealand). The specific surface of halloysite is $28.64 \mathrm{~m}^{2} \cdot \mathrm{g}^{-1}$ [28].

\subsection{Preparation of Multilayer Nanocomposites}

The multilayer nanocomposites were prepared through a sequential casting method. Firstly, we prepared the solutions of chitosan and HPC in two different solvents (water and ethanol, respectively) 
and an aqueous dispersion of halloysite. The concentrations and the solvent media used for the biopolymer solution are reported in Table 1.

Table 1. The concentration and solvent medium for the biopolymer solutions.

\begin{tabular}{ccc}
\hline Material & Solvent & Concentration (wt \%) \\
\hline Hydroxypropyl cellulose (HPC) & ethanol & 2.01 \\
Chitosan & water $(\mathrm{pH}=3.5)$ & 1.02 \\
\hline
\end{tabular}

Stable polymer solutions were obtained by stirring overnight at $30^{\circ} \mathrm{C}$. As concerns chitosan, the $\mathrm{pH}$ of the solution was fixed at 3.5 by adding dropwise $0.1 \mathrm{~mol} \cdot \mathrm{dm}^{-3}$ acetic acid because of the very low solubility of the biopolymer at neutral $\mathrm{pH}$ [29]. Then, halloysite was dispersed in the chitosan solution by sonication and subsequent magnetically stirring overnight at $30^{\circ} \mathrm{C}$. The concentration of halloysite dispersion was $5 \mathrm{wt} \%$. Consequently, the chitosan/HNTs ratio was fixed at 0.2. Chitosan acted as the stabilizing agent of the HNT's aqueous dispersions.

The nanocomposite films with the multilayer structure (a layer of chitosan/HNTs between two layers of HPC) were obtained through the subsequent deposition of the HPC solution and the chitosan/HNTs dispersion as follows: (1) HPC; (2) chitosan/HNTs; (3) HPC.

In detail, the first layer of the nanocomposite was obtained by pouring the HPC solution into a glass Petri dish at $30^{\circ} \mathrm{C}$ to evaporate ethanol until the weight was constant. Then, the chitosan/HNTs aqueous dispersion was deposited on the HPC dried film and kept at $30^{\circ} \mathrm{C}$ to evaporate water and, consequently, we obtained the second layer. Finally, the casting of the HPC was conducted on the chitosan/HNTs layer allowing to fabricate a sandwich-like structure. It should be noted that the very low solubility of chitosan in ethanol ensures to obtain nanocomposites with a multilayer morphology.

The composition of the nanocomposites was systematically varied by changing the amounts of HPC solutions and chitosan/HNTs used in the sequential casting procedure (Table 2). The variable composition of the nanocomposites was expressed by the weight ratio $\left(\mathrm{R}_{(\mathrm{C}+\mathrm{H}) / \mathrm{HPC}}\right)$ between the middle layer (chitosan + HNTs) and outer layers (HPC).

Table 2. The composition of the nanocomposites and the corresponding amounts of hydroxypropyl cellulose (HPC) solutions and chitosan/halloysite nanotubes (HNTs) dispersions used in the sequential casting.

\begin{tabular}{cccc}
\hline $\mathbf{R}_{(\mathbf{C}+\mathbf{H}) / \mathbf{H P C}}$ & $\begin{array}{c}\text { Amount of HPC } \\
\text { Solution (First Layer)/g }\end{array}$ & $\begin{array}{c}\text { Amount of Chitosan/HNTs } \\
\text { Dispersion (Second Layer)/g }\end{array}$ & $\begin{array}{c}\text { Amount of HPC Solution } \\
\text { (Third Layer)/g }\end{array}$ \\
\hline 0.92 & 8.18 & 4.96 & 8.02 \\
1.89 & 8.15 & 10.24 & 8.07 \\
2.81 & 8.05 & 15.03 & 8.00 \\
\hline
\end{tabular}

\subsection{Methods}

\subsubsection{Thermogravimetry}

The Q5000 IR apparatus (TA Instruments, New Castle, DE, USA) was employed to perform thermogravimetry (TG) measurements, which were carried out under a nitrogen flows of 25 and $10 \mathrm{~cm}^{3} \cdot \mathrm{min}^{-1}$ for the sample and the balance, respectively. The sample (ca. $5 \mathrm{mg}$ ) was loaded in a platinum crucible and heated from room temperature to $900{ }^{\circ} \mathrm{C}$ at variable heating rates $(\beta)$, which were $5,10,15$, and $20^{\circ} \mathrm{C} \cdot \mathrm{min}^{-1}$. The analysis of TG data allowed for the determination of the activation energy $\left(\mathrm{E}_{\mathrm{a}}\right)$ of HPC degradation. The Curie temperatures of standards (nickel, cobalt, and their alloys) were considered for the temperature calibration. 


\subsubsection{Differential Scanning Calorimetry}

The DSC 2920 CE apparatus (TA Instruments) was used to conduct Differential scanning calorimetry (DSC) measurements. The apparatus was calibrated using the using the melting enthalpy of standard indium $\left(28.71 \mathrm{~J} \cdot \mathrm{g}^{-1}\right)$. Both the temperature and the power calibration were estimated at variable heating rates in agreement with the recent IUPAC technical report [52]. The sample (ca. $2 \mathrm{mg}$ ) was loaded in an aluminum pan. The measurements were performed in the static air from 0 to $600{ }^{\circ} \mathrm{C}$ at the heating rate of $10^{\circ} \mathrm{C} \cdot \mathrm{min}^{-1}$.

\subsubsection{Scanning Electron Microscopy}

A microscope ESEM FEI QUANTA 200F (Hillsboro, OR, USA) was used to investigate the morphological characteristics of the nanocomposite, which were previously coated with gold in argon by means of an Edwards Sputter Coater S150A (Edwards, Burgess Hill, UK) to avoid charging under the electron beam. The measurements were conducted in a high vacuum $\left(<6 \times 10^{-4} \mathrm{~Pa}\right)$, while the energy of the beam and the working distance were set at $25 \mathrm{kV}$ and $10 \mathrm{~mm}$, respectively.

\section{Results and Discussion}

\subsection{Multilayer Structure the Nanocomposites}

Figure 1 shows the schematic representation and the scanning electron microscope (SEM) image for the prepared multilayer nanocomposites.

a)

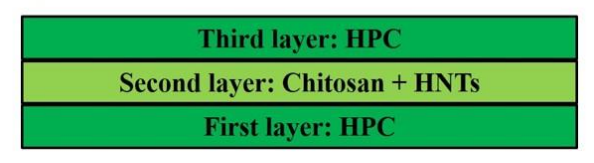

b)

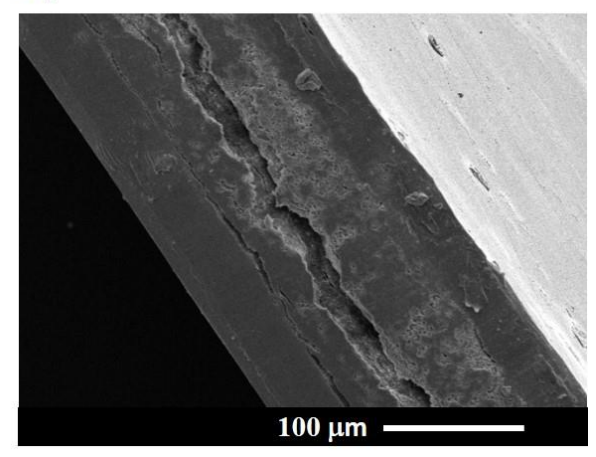

Figure 1. The sketch of the multilayer structure of the nanocomposites (a) and the scanning electron microscope (SEM) image for the composite materials with $\mathrm{R}_{(\mathrm{C}+\mathrm{H}) / \mathrm{HPC}}=2.81(\mathbf{b})$.

The thickness of the outer HPC layers was kept constant, while the intermediate layer of the chitosan/HNTs was systematically changed. Regarding the HPC layers, the thickness $\left(\mathrm{h}_{(\mathrm{HPC})}\right)$ was calculated as

$$
\mathrm{h}_{(\mathrm{HPC})}=\mathrm{m}_{\mathrm{HPC}} /\left(\delta_{\mathrm{HPC}} \cdot \pi \cdot \mathrm{r}^{2}\right),
$$

where $r$ is the radius of the Petri dish used for the preparation of the nanocomposites, while $m_{H P C}$ and $\delta_{\mathrm{HPC}}$ are the mass and the density of HPC, respectively. The thickness of the intermediate layer composed by chitosan and HNTs $\left(\mathrm{h}_{\mathrm{C}+\mathrm{H}}\right)$ was determined by the equations

$$
\mathrm{h}^{*}(\mathrm{C}+\mathrm{H})=\mathrm{h}_{(\mathrm{C})}+\mathrm{h}_{(\mathrm{H})},
$$




$$
\begin{aligned}
& \mathrm{h}_{(\mathrm{C})}=\mathrm{m}_{\mathrm{C}} /\left(\delta_{\mathrm{C}} \cdot \pi \cdot \mathrm{r}^{2}\right), \\
& \mathrm{h}_{(\mathrm{H})}=\mathrm{m}_{\mathrm{H}} /\left(\delta_{\mathrm{H}} \cdot \pi \cdot \mathrm{r}^{2}\right),
\end{aligned}
$$

where $m_{C}$ and $\delta_{C}$ are the mass and the density of chitosan, respectively, and $m_{H}$ and $\delta_{H}$ are the mass and the density of halloysite, respectively. It should be noted that the described approach (Equations (2)-(4)) assumes that the densities of chitosan and halloysite are not altered by their reciprocal interactions. The sum of the calculated thicknesses for each composed layers is in agreement with the total thickness (experimentally determined by a micrometer) of the nanocomposite film. Table 3 collects the thickness values for the prepared nanocomposites.

Table 3. The thicknesses of the films, the outer HPC layers, and intermediate chitosan/HNT layer for

\begin{tabular}{|c|c|c|c|c|}
\hline $\mathbf{R}_{(\mathrm{C}+\mathrm{H}) / \mathrm{HPC}}$ & $\begin{array}{c}h_{(\mathrm{HPC})} \\
\text { (First Layer)/ } / \mu \mathrm{m}\end{array}$ & $\begin{array}{c}\mathrm{h}_{(\mathrm{HPC})} \\
\text { (Third Layer) } / \mu \mathrm{m}\end{array}$ & $\begin{array}{c}\mathrm{h}_{\mathrm{C}+\mathrm{H}} \\
\text { (Middle Layer) } / \mu \mathrm{m}\end{array}$ & $\begin{array}{c}\text { Nanocomposite } \\
\text { Thickness/ } / \mu \mathrm{m}\end{array}$ \\
\hline 0.92 & 71.2 & 69.8 & 2.67 & 144 \\
\hline 1.89 & 70.9 & 70.3 & 5.52 & 147 \\
\hline 2.81 & 70.1 & 69.7 & 8.11 & 149 \\
\hline
\end{tabular}
the prepared nanocomposites.

\subsection{Thermal Properties of the Nanocomposites}

\subsubsection{Thermogravimetric Analysis: Thermal Behavior under Inert Atmosphere}

Figure 2 shows the thermogravimetric curve (determined at $\beta=10^{\circ} \mathrm{C} \cdot \mathrm{min}^{-1}$ ) of the nanocomposite at variable compositions.

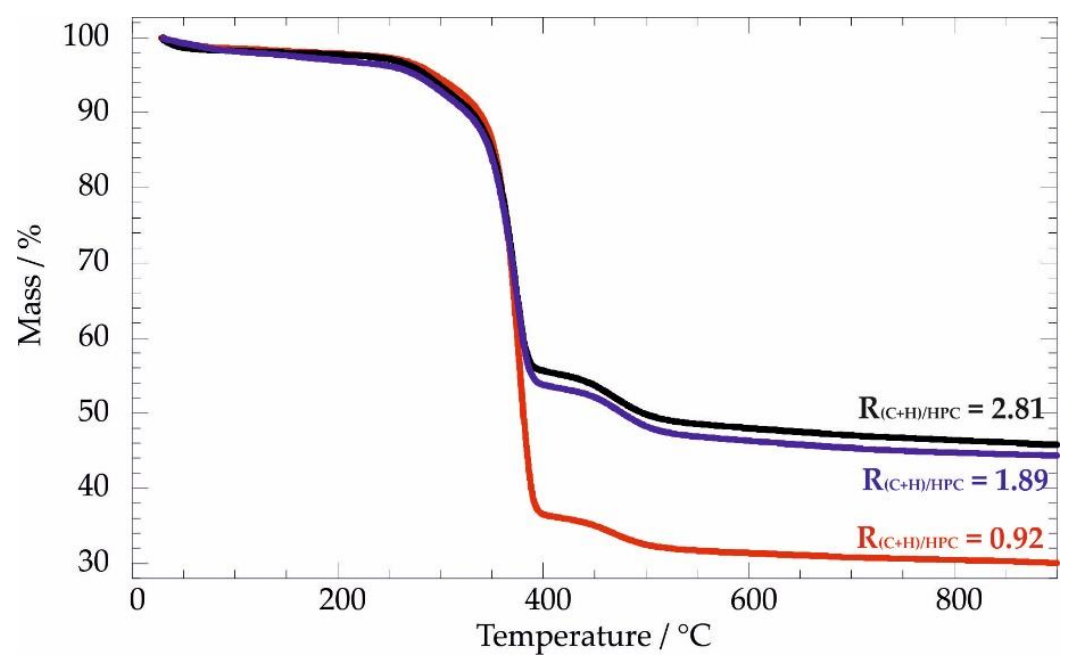

Figure 2. The thermogravimetric curves for the nanocomposites at variable compositions.

We observed three different mass losses: (1) the first mass loss $\left(\mathrm{ML}_{150}\right)$ occurs in the temperature range between 25 and $150{ }^{\circ} \mathrm{C}$ as a consequence of the evaporation of the water physically adsorbed on the materials; (2) the second mass loss (ML400) takes place at the temperature interval $200-400{ }^{\circ} \mathrm{C}$ because of the decomposition of the organic moieties; (3) the third mass loss (ML550) occurs in a temperature range of $420-550{ }^{\circ} \mathrm{C}$. As reported in the literature [34], the latter is due to the expulsion of the two water molecules that are present in the halloysite interlayer. Table 4 compares the mass losses for the nanocomposite materials with those for pure hydroxypropyl cellulose. 
Table 4. The mass losses and residual masses at $900{ }^{\circ} \mathrm{C}$ for pure $\mathrm{HPC}$ and nanocomposites determined by thermogravimetry (TG) measurements at $\beta=10^{\circ} \mathrm{C} \cdot \mathrm{min}^{-1}$.

\begin{tabular}{ccccccc}
\hline $\mathbf{R}_{\mathbf{( C + H ) / H P C}}$ & $\mathbf{M L}_{\mathbf{1 5 0}} / \%$ & $\mathbf{M L}_{\mathbf{4 0 0}} / \%$ & $\mathbf{M L}_{\mathbf{6 0 0}} / \%$ & $\mathbf{M R}_{\mathbf{9 0 0}} / \%$ & $\mathrm{~T}_{\mathbf{C H I T}} /{ }^{\circ} \mathbf{C}$ & $\mathbf{T}_{\mathbf{H P C}} /{ }^{\circ} \mathbf{C}$ \\
\hline 0 & 0.65 & 92.4 & $/$ & 4.07 & 289.2 & 369.7 \\
0.92 & 1.74 & 61.3 & 4.28 & 30.1 & 290.2 & 376.4 \\
1.89 & 1.83 & 43.2 & 6.33 & 44.8 & 291.6 & 373.4 \\
2.81 & 2.31 & 42.1 & 6.49 & 45.8 & 286.5 & 374.5 \\
\hline
\end{tabular}

The presence of the intermediate layer composed of chitosan and HNT generated an increase of the $\mathrm{ML}_{150}$ indicating an enhancement of the affinity towards water due to the hydrophilic nature of halloysite. As expected, the $\mathrm{ML}_{400}$ value was reduced in the nanocomposites, while the opposite effect was detected for $\mathrm{ML}_{600}$ results. Compared with neat $\mathrm{HPC}, \mathrm{MR}_{900}$ is much larger in the composite materials because of the inorganic clay nanotubes, which do not undergo through a complete decomposition even at very high temperatures [34]. The analysis of the differential thermogravimetric (DTG) curves (Figure 3) provided a clearer description of the several degradation steps occurring in the nanocomposites.

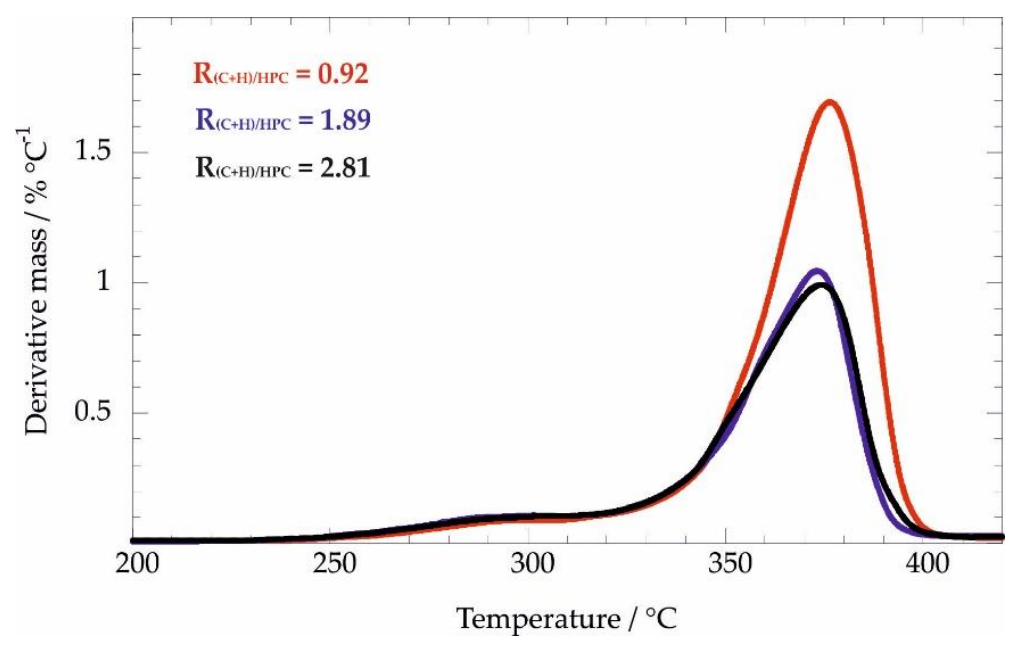

Figure 3. The differential thermogravimetric curves for the nanocomposites at variable compositions.

In the range $200-400{ }^{\circ} \mathrm{C}$, DTG curves showed a shoulder (centered at ca. $290{ }^{\circ} \mathrm{C}$ ) and a peak (centered at ca. $370{ }^{\circ} \mathrm{C}$ ) that can be mostly attributed to the thermal degradation of chitosan and HPC, respectively. Accordingly, we determined the HPC degradation temperature $\left(\mathrm{T}_{\mathrm{HPC}}\right)$ from the maximum of the DTG peaks, while the chitosan degradation temperature $\left(\mathrm{T}_{\mathrm{CHIT}}\right)$ was estimated from the maximum of the DTG shoulders. As evidenced in Table 4, a slight thermal stabilization of HPC was observed in the multilayer nanocomposites. Generally, an increase of the polymer resistance to thermal degradation in nanocomposite systems is ascribed to the barrier effect of the nanofillers towards the volatile products generated by the polymer decomposition [34,46]. Regarding chitosan, the degradation temperatures are similar to that of pure chitosan $\left(290.2^{\circ} \mathrm{C}\right)$.

The kinetic aspects of the polymer degradation were studied by using a non-isothermal thermogravimetric method. To this purpose, we performed TG measurements at variable heating rates and the obtained data in the range $200-400{ }^{\circ} \mathrm{C}$ were analyzed by means of the Friedman approach, which can be expressed by the equation

$$
\ln \left(\frac{\beta \mathrm{d} \alpha}{\mathrm{dT}}\right)=\ln [\operatorname{Af}(\alpha)]-\frac{\mathrm{E}_{\mathrm{a}}}{\mathrm{RT}}
$$


where $\alpha$ is the conversion degree, while $\mathrm{A}$ and $\mathrm{R}$ represent the pre-exponential factor and the gas constant, respectively. Moreover, $f(\alpha)$ is the function that relates the specific degradation mechanism with the conversion degree. Based on Equation (5), the activation energy $\left(E_{a}\right)$ can be determined by the slope of the $\ln (\beta \mathrm{d} \alpha / \mathrm{dT})$ vs. the $1 / \mathrm{T}$ trends. As a general result, we observed that $\mathrm{E}_{\mathrm{a}}$ is constant with $\alpha$ for all of the investigated materials. On this basis, we calculated the average $E_{a}$ values, which are presented in Figure 4. In general, the presence of the intermediate layer did not significantly affect the kinetics of HPC degradation.

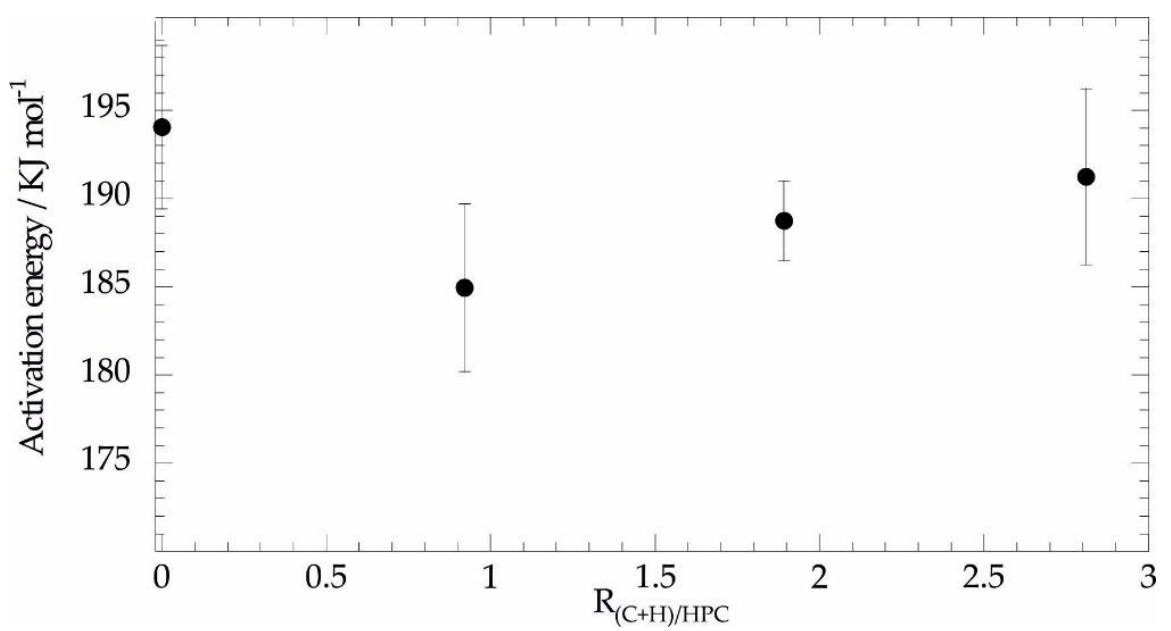

Figure 4. The average activation energy of hydroxypropyl cellulose (HPC) degradation as a function of the weight ratio between the middle layer (chitosan + halloysite nanotubes (HNTs)) and the outer layers (HPC).

\subsubsection{Oxidative Degradation of Nanocomposites by Differential Scanning Calorimetry}

The oxidative degradation of the nanocomposite materials was investigated by means of DSC measurements conducted statically. As shown in Figure 5, the DSC curves of the multilayer systems present an exothermic reaction due to the degradation of organic components under the oxidative conditions.

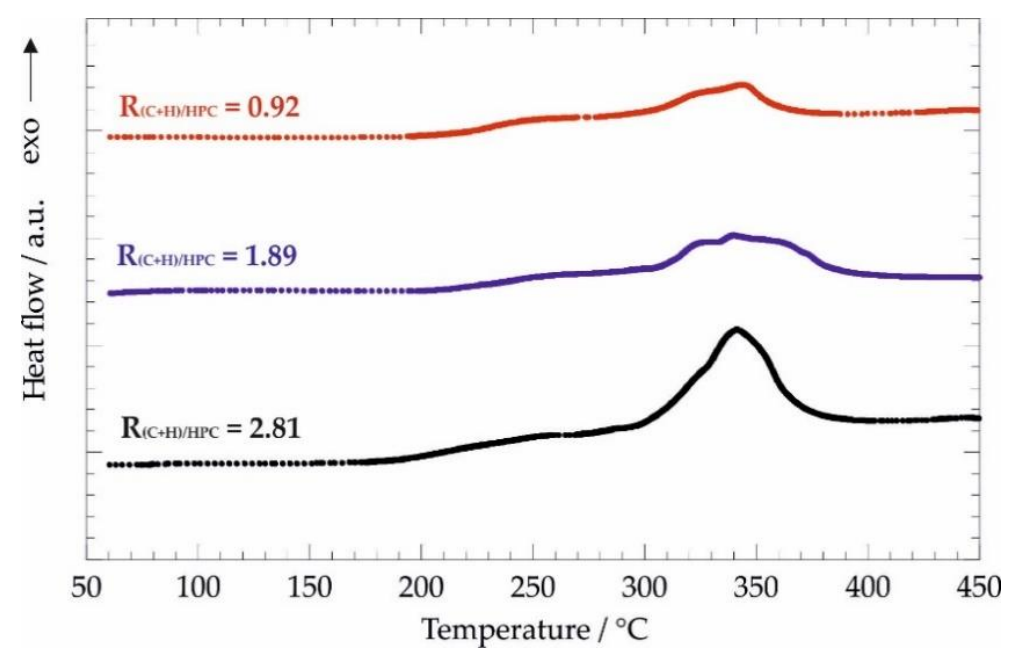

Figure 5. The differential scanning calorimetry (DSC) curves for nanocomposites at variable compositions. 
The analysis of the DSC peaks allowed for the exploration of the thermodynamics of the oxidative degradation. In particular, we determined the temperature $\left(\mathrm{T}_{\mathrm{ox}}\right)$ and the enthalpy variation $\left(\Delta \mathrm{H}_{\mathrm{ox}}\right)$ of the oxidative degradation by the maximum and the integration of the exothermic peaks. Figure 6 displays the dependence of both $\mathrm{T}_{\mathrm{ox}}$ and $\Delta \mathrm{H}_{\mathrm{ox}}$ on the weight ratio between the middle layer (chitosan + HNTs) and the outer layers (HPC).

Compared with pure HPC, the nanocomposites gave evidence to the reduction of both parameters. The $\Delta \mathrm{H}_{\mathrm{ox}}$ decrease indicates that the presence of the middle layer composed of chitosan and halloysite lowered the quantity of the heat released during the exothermic process, which is represented by the oxidative degradation. This result gives evidence that the addition of chitosan/HNTs between the HPC layers produces a fire retardant action as expected for well-defined multilayer materials.

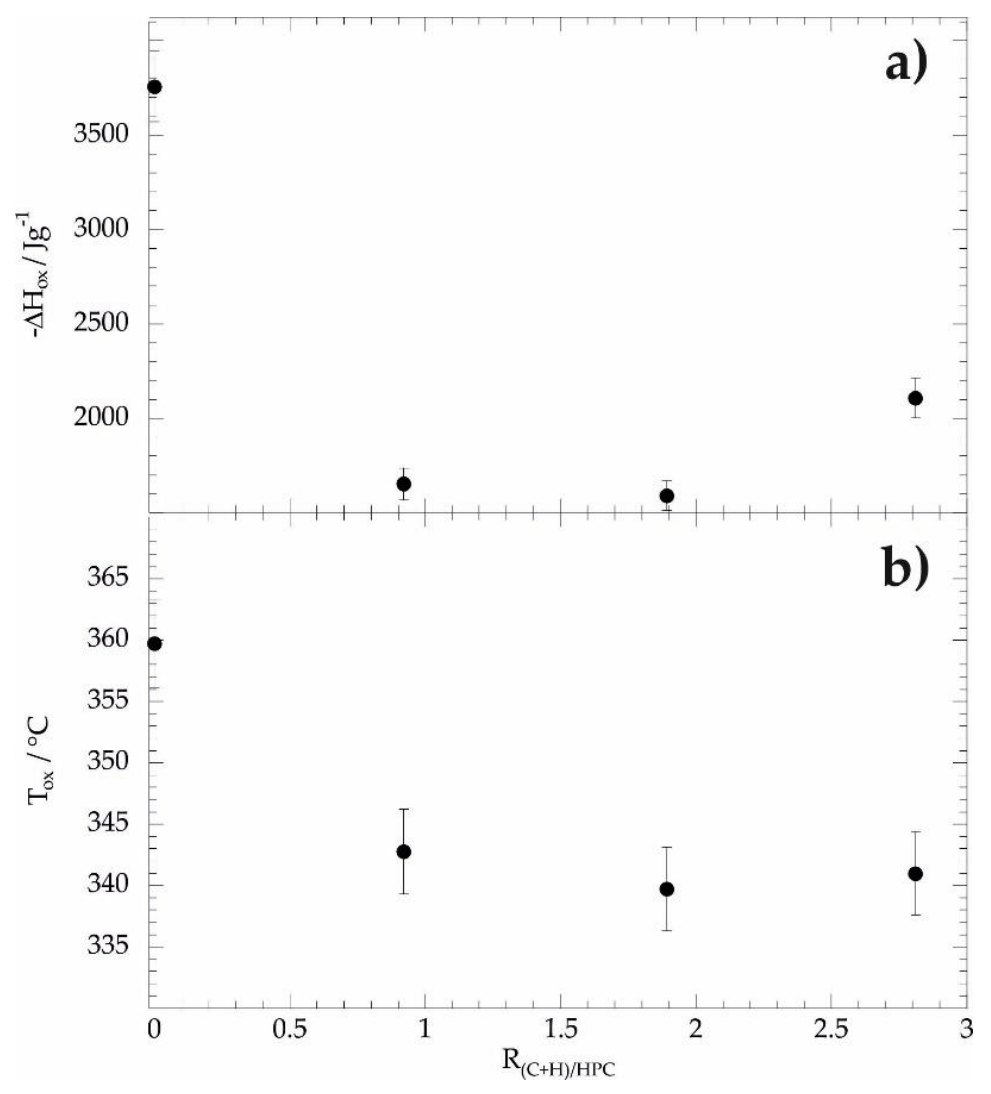

Figure 6. The enthalpy variation (a) and temperature (b) of oxidative degradation as functions of the weight ratio between the middle layer (chitosan $+\mathrm{HNTs}$ ) and outer layers (HPC).

\section{Conclusions}

Nanocomposites with a multilayer structure were successfully prepared by the sequential casting of ethanol solutions of HPC and the aqueous dispersion of chitosan/halloysite. The composition of the nanocomposites was systematically varied in order to control the thickness of the intermediate layer composed of chitosan and halloysite nanotubes (HNTs). The thermal properties of the nanocomposites were affected by the peculiar multilayer structure of the biocomposite films. Thermogravimetry (TG) measurements performed under an inert atmosphere gave evidence to a slight increase of the HPC thermal stability in the nanocomposites. TG data collected at variable heating rates were analyzed by the non-isothermal Friedman method, which showed that the activation energy of the HPC degradation is not significantly affected by the addition of the chitosan/HNT layer.

The oxidative degradation of the nanocomposites was studied by Differential Scanning Calorimetry (DSC), which highlighted a reduction in the temperature, as well as the enthalpy variation 
for the investigated exothermic process in the multilayer systems. Interestingly, the decrease of the enthalpy change indicates that the chitosan/halloysite layer generates a flame retardant action on the biomaterials. In conclusion, this work describes an easy strategy to fabricate multilayer bio-nanocomposites with promising thermal characteristics.

Author Contributions: G.L., and S.M. conceived and directed the project. G.C. analysed the data and wrote the paper. V.B. and F.P. prepared the nanocomposites and conducted TGA/DSC experiments.

Acknowledgments: The work was financially supported by the University of Palermo.

Conflicts of Interest: The authors declare no conflict of interest.

\section{References}

1. Fix, D.; Andreeva, D.V.; Lvov, Y.M.; Shchukin, D.G.; Möhwald, H. Application of inhibitor-loaded halloysite nanotubes in active anti-corrosive coatings. Adv. Funct. Mater. 2009, 19, 1720-1727. [CrossRef]

2. Lvov, Y.; Aerov, A.; Fakhrullin, R. Clay nanotube encapsulation for functional biocomposites. Adv. Colloid Interface Sci. 2014, 207, 189-198. [CrossRef] [PubMed]

3. Joshi, A.; Abdullayev, E.; Vasiliev, A.; Volkova, O.; Lvov, Y. interfacial modification of clay nanotubes for the sustained release of corrosion inhibitors. Langmuir 2013, 29, 7439-7448. [CrossRef] [PubMed]

4. Cavallaro, G.; Donato, D.I.; Lazzara, G.; Milioto, S. Films of halloysite nanotubes sandwiched between two layers of biopolymer: From the morphology to the dielectric, thermal, transparency, and wettability properties. J. Phys. Chem. C 2011, 115, 20491-20498. [CrossRef]

5. Makaremi, M.; Pasbakhsh, P.; Cavallaro, G.; Lazzara, G.; Aw, Y.K.; Lee, S.M.; Milioto, S. Effect of morphology and size of halloysite nanotubes on functional pectin bionanocomposites for food packaging applications. ACS Appl. Mater. Interfaces 2017, 9, 17476-17488. [CrossRef] [PubMed]

6. Du, M.; Guo, B.; Jia, D. Newly emerging applications of halloysite nanotubes: A review. Polym. Int. 2010, 59, 574-582. [CrossRef]

7. Zhao, Y.; Abdullayev, E.; Vasiliev, A.; Lvov, Y. Halloysite nanotubule clay for efficient water purification. J. Colloid Interface Sci. 2013, 406, 121-129. [CrossRef] [PubMed]

8. Zhao, M.; Liu, P. Adsorption behavior of methylene blue on halloysite nanotubes. Microporous Mesoporous Mater. 2008, 112, 419-424. [CrossRef]

9. Owoseni, O.; Nyankson, E.; Zhang, Y.; Adams, S.J.; He, J.; McPherson, G.L.; Bose, A.; Gupta, R.B.; John, V.T. Release of surfactant cargo from interfacially-active halloysite clay nanotubes for oil spill remediation. Langmuir 2014, 30, 13533-13541. [CrossRef] [PubMed]

10. Panchal, A.; Swientoniewski, L.T.; Omarova, M.; Yu, T.; Zhang, D.; Blake, D.A.; John, V.; Lvov, Y.M. Bacterial proliferation on clay nanotube Pickering emulsions for oil spill bioremediation. Colloids Surf. B Biointerfaces 2018, 164, 27-33. [CrossRef] [PubMed]

11. Cavallaro, G.; Gianguzza, A.; Lazzara, G.; Milioto, S.; Piazzese, D. Alginate gel beads filled with halloysite nanotubes. Appl. Clay Sci. 2013, 72, 132-137. [CrossRef]

12. Liu, Y.; Guan, H.; Zhang, J.; Zhao, Y.; Yang, J.-H.; Zhang, B. Polydopamine-coated halloysite nanotubes supported AgPd nanoalloy: An efficient catalyst for hydrolysis of ammonia borane. Int. J. Hydrog. Energy 2018, 43, 2754-2762. [CrossRef]

13. Liu, Y.; Zhang, J.; Guan, H.; Zhao, Y.; Yang, J.-H.; Zhang, B. Preparation of bimetallic Cu-Co nanocatalysts on poly(diallyldimethylammonium chloride) functionalized halloysite nanotubes for hydrolytic dehydrogenation of ammonia borane. Appl. Surf. Sci. 2018, 427, 106-113. [CrossRef]

14. Wang, Q.; Wang, Y.; Zhao, Y.; Zhang, B.; Niu, Y.; Xiang, X.; Chen, R. Fabricating roughened surfaces on halloysite nanotubes via alkali etching for deposition of high-efficiency Pt nanocatalysts. CrystEngComm 2015, 17, 3110-3116. [CrossRef]

15. Sadjadi, S.; Hosseinnejad, T.; Malmir, M.; Heravi, M.M. Cu@furfural imine-decorated halloysite as an efficient heterogeneous catalyst for promoting ultrasonic-assisted $\mathrm{A}^{3}$ and $\mathrm{KA}^{2}$ coupling reactions: A combination of experimental and computational study. New J. Chem. 2017, 41, 13935-13951. [CrossRef]

16. Chang, C.W.; van Spreeuwel, A.; Zhang, C.; Varghese, S. PEG/clay nanocomposite hydrogel: A mechanically robust tissue engineering scaffold. Soft Matter 2010, 6, 5157-5164. [CrossRef] 
17. Fakhrullin, R.F.; Lvov, Y.M. Halloysite clay nanotubes for tissue engineering. Nanomedicine 2016, 11, 2243-2246. [CrossRef] [PubMed]

18. Liu, M.; Wu, C.; Jiao, Y.; Xiong, S.; Zhou, C. Chitosan-halloysite nanotubes nanocomposite scaffolds for tissue engineering. J. Mater. Chem. B 2013, 1, 2078-2089. [CrossRef]

19. Cavallaro, G.; Danilushkina, A.A.; Evtugyn, V.G.; Lazzara, G.; Milioto, S.; Parisi, F.; Rozhina, E.V.; Fakhrullin, R.F. Halloysite nanotubes: Controlled access and release by smart gates. Nanomaterials 2017, 7, 199. [CrossRef] [PubMed]

20. Cavallaro, G.; Lazzara, G.; Milioto, S.; Parisi, F.; Sparacino, V. Thermal and dynamic mechanical properties of beeswax-halloysite nanocomposites for consolidating waterlogged archaeological woods. Polym. Degrad. Stab. 2015, 120, 220-225. [CrossRef]

21. Cavallaro, G.; Lisi, R.; Lazzara, G.; Milioto, S. Polyethylene glycol/clay nanotubes composites. J. Therm. Anal. Calorim. 2013, 112, 383-389. [CrossRef]

22. Gorrasi, G.; Bugatti, V.; Vittoria, V. Pectins filled with LDH-antimicrobial molecules: Preparation, characterization and physical properties. Carbohydr. Polym. 2012, 89, 132-137. [CrossRef] [PubMed]

23. Cavallaro, G.; Lazzara, G.; Konnova, S.; Fakhrullin, R.; Lvov, Y. Composite films of natural clay nanotubes with cellulose and chitosan. Green Mater. 2014, 2, 232-242. [CrossRef]

24. Kryuchkova, M.; Danilushkina, A.; Lvov, Y.; Fakhrullin, R. Evaluation of toxicity of nanoclays and graphene oxide in vivo: A Paramecium caudatum study. Environ. Sci. Nano 2016, 3, 442-452. [CrossRef]

25. Wang, X.; Gong, J.; Rong, R.; Gui, Z.; Hu, T.; Xu, X. Halloysite nanotubes-induced al accumulation and fibrotic response in lung of mice after 30-day repeated oral administration. J. Agric. Food Chem. 2018, 66, 2925-2933. [CrossRef] [PubMed]

26. Lvov, Y.; Wang, W.; Zhang, L.; Fakhrullin, R. Halloysite clay nanotubes for loading and sustained release of functional compounds. Adv. Mater. 2016, 28, 1227-1250. [CrossRef] [PubMed]

27. Joussein, E.; Petit, S.; Churchman, G.J.; Theng, B.; Righi, D.; Delvaux, B. Halloysite clay minerals-A review. Clay Miner. 2005, 40, 383-426. [CrossRef]

28. Cavallaro, G.; Chiappisi, L.; Pasbakhsh, P.; Gradzielski, M.; Lazzara, G. A structural comparison of halloysite nanotubes of different origin by Small-angle neutron scattering (SANS) and electric birefringence. Appl. Clay Sci. 2018, 160, 71-80. [CrossRef]

29. Bertolino, V.; Cavallaro, G.; Lazzara, G.; Milioto, S.; Parisi, F. Biopolymer-targeted adsorption onto halloysite nanotubes in aqueous media. Langmuir 2017, 33, 3317-3323. [CrossRef] [PubMed]

30. Kalay, S.; Stetsyshyn, Y.; Lobaz, V.; Harhay, K.; Ohar, H.; Çulha, M. Water-dispersed thermo-responsive boron nitride nanotubes: Synthesis and properties. Nanotechnology 2016, 27, 035703. [CrossRef] [PubMed]

31. Zhao, Y.; Cavallaro, G.; Lvov, Y. Orientation of charged clay nanotubes in evaporating droplet meniscus. J. Colloid Interface Sci. 2015, 440, 68-77. [CrossRef] [PubMed]

32. Liu, M.; Huo, Z.; Liu, T.; Shen, Y.; He, R.; Zhou, C. Self-assembling halloysite nanotubes into concentric ring patterns in a sphere-on-flat geometry. Langmuir 2017, 33, 3088-3098. [CrossRef] [PubMed]

33. Cavallaro, G.; Grillo, I.; Gradzielski, M.; Lazzara, G. Structure of hybrid materials based on halloysite nanotubes filled with anionic surfactants. J. Phys. Chem. C 2016, 120, 13492-13502. [CrossRef]

34. Bertolino, V.; Cavallaro, G.; Lazzara, G.; Merli, M.; Milioto, S.; Parisi, F.; Sciascia, L. Effect of the biopolymer charge and the nanoclay morphology on nanocomposite materials. Ind. Eng. Chem. Res. 2016, 55, 7373-7380. [CrossRef]

35. Gorrasi, G. Dispersion of halloysite loaded with natural antimicrobials into pectins: Characterization and controlled release analysis. Carbohydr. Polym. 2015, 127, 47-53. [CrossRef] [PubMed]

36. De Silva, R.T.; Pasbakhsh, P.; Goh, K.L.; Chai, S.-P.; Ismail, H. Physico-chemical characterisation of chitosan/halloysite composite membranes. Polym. Test. 2013, 32, 265-271. [CrossRef]

37. Ali, A.; Ahmed, S. A review on chitosan and its nanocomposites in drug delivery. Int. J. Biol. Macromol. 2018, 109, 273-286. [CrossRef] [PubMed]

38. Liu, M.; Zhang, Y.; Wu, C.; Xiong, S.; Zhou, C. Chitosan/halloysite nanotubes bionanocomposites: Structure, mechanical properties and biocompatibility. Int. J. Biol. Macromol. 2012, 51, 566-575. [CrossRef] [PubMed]

39. Huang, B.; Liu, M.; Zhou, C. Chitosan composite hydrogels reinforced with natural clay nanotubes. Carbohydr. Polym. 2017, 175, 689-698. [CrossRef] [PubMed]

40. Gorrasi, G.; Pantani, R.; Murariu, M.; Dubois, P. PLA/Halloysite nanocomposite films: water vapor barrier properties and specific key characteristics. Macromol. Mater. Eng. 2014, 299, 104-115. [CrossRef] 
41. Bertolino, V.; Cavallaro, G.; Lazzara, G.; Milioto, S.; Parisi, F. Halloysite nanotubes sandwiched between chitosan layers: Novel bionanocomposites with multilayer structures. New J. Chem. 2018, 42, 8384-8390. [CrossRef]

42. Lvov, Y.; Abdullayev, E. Functional polymer-clay nanotube composites with sustained release of chemical agents. Prog. Polym. Sci. 2013, 38, 1690-1719. [CrossRef]

43. Terekhova, I.V. Comparative thermodynamic study on complex formation of native and hydroxypropylated cyclodextrins with benzoic acid. Thermochim. Acta 2011, 526, 118-121. [CrossRef]

44. Terekhova, I.V.; Romanova, A.O.; Kumeev, R.S.; Fedorov, M.V. Selective $\mathrm{Na}^{+} / \mathrm{K}^{+}$effects on the formation of $\alpha$-cyclodextrin complexes with aromatic carboxylic acids: competition for the guest. J. Phys. Chem. B 2010, 114, 12607-12613. [CrossRef] [PubMed]

45. Blanco, I.; Abate, L.; Bottino, F.A.; Bottino, P. Thermal behaviour of a series of novel aliphatic bridged polyhedral oligomeric silsesquioxanes (POSSs)/polystyrene (PS) nanocomposites: The influence of the bridge length on the resistance to thermal degradation. Polym. Degrad. Stab. 2014, 102, 132-137. [CrossRef]

46. Du, M.; Guo, B.; Jia, D. Thermal stability and flame retardant effects of halloysite nanotubes on poly(propylene). Eur. Polym. J. 2006, 42, 1362-1369. [CrossRef]

47. Blanco, I.; Abate, L.; Bottino, F.A.; Bottino, P. Thermal degradation of hepta cyclopentyl, mono phenyl-polyhedral oligomeric silsesquioxane (hcp-POSS)/polystyrene (PS) nanocomposites. Polym. Degrad. Stab. 2012, 97, 849-855. [CrossRef]

48. Budrugeac, P.; Cucos, A.; Miu, L. The use of thermal analysis methods for authentication and conservation state determination of historical and/or cultural objects manufactured from leather. J. Therm. Anal. Calorim. 2011, 104, 439-450. [CrossRef]

49. Vyazovkin, S.; Dranca, I.; Fan, X.; Advincula, R. Degradation and relaxation kinetics of polystyrene-Clay nanocomposite prepared by surface initiated polymerization. J. Phys. Chem. B 2004, 108, 11672-11679. [CrossRef]

50. Vyazovkin, S.; Chrissafis, K.; Di Lorenzo, M.L.; Koga, N.; Pijolat, M.; Roduit, B.; Sbirrazzuoli, N.; Suñol, J.J. ICTAC Kinetics Committee recommendations for collecting experimental thermal analysis data for kinetic computations. Thermochim. Acta 2014, 590, 1-23. [CrossRef]

51. Palacios, A.; De Gracia, A.; Haurie, L.; Cabeza, L.F.; Fernández, A.I.; Barreneche, C. Study of the thermal properties and the fire performance of flame retardant-organic PCM in bulk form. Materials 2018, 11, 117. [CrossRef] [PubMed]

52. Lee, H.; Fasulo, P.D.; Rodgers, W.R.; Paul, D.R. TPO based nanocomposites. Part 2. Thermal expansion behavior. Polymer 2006, 47, 3528-3539. [CrossRef] 